\title{
Connecting the private and the public: Pregnancy, exclusion and the expansion of schooling in Africa
}

\section{Elaine Unterhalter}

\section{Abstract}

In a number of countries in Africa young women who become pregnant are excluded from school. This paper presents a critique of policy and practice in this area drawing partly on Diana Leonard's scholarship concerning the relational dynamic of gender, generation, social division, and household forms. Much of the policy prescription of large global organisations concerned with the expansion of secondary schooling in Africa does not sufficiently take account of the connection between the gender dynamics of the private and public outlined in Leonard's work . In showing some of the effects of this oversight the paper draws on data from research studies in five countries in Africa (Kenya, Tanzania, South Africa, Nigeria and Ghana) to show how aspects of silence, evasion, and stereoptyping often characterise teachers' and education officials' reflections on youth and pregnancy. Young women's concerns with the risk of pregnancy are often given inadequate attention, while harsh actions to shame young women who become pregnant are reported. The importance of working across sectors to link social policy in this area are shown to be difficult and in need of much more focussed resource.

Keywords: Kenya, South Africa, Tanzania, school exclusions, pregnancy, gender

In many countries in Africa girls or young women who become pregnant are excluded from school. Demographic Household Survey (DHS) data from 23 countries in Sub-Saharan Africa reviewed in 2004 led to a conclusion that $18 \%$ of young women dropped out of secondary school because of pregnancy. (Eloundou-Enyegue 2004:510). However, Lloyd \& Mensch $(2008,3)$ note that DHS surveys probably under-enumerate these pregnancies, as the consequences for young women in reporting them may be dire. They also raise some questions about the review methods used in the 2004 study. Their own analysis of DHS data for 20 African countries indicates that pregnancy is cited as the main reason for young women aged 20-24 not completing school in very different proportions. The lowest proportion giving this reason is $1 \%$ of the age group in Niger, while the highest is $31 \%$ in South Africa (Lloyd and Mensch, 2008, 5). While the details of how to approach these calculations is beyond the scope of this paper, the numbers excluded are a matter of concern. So too are the ways in which policy responses are framed. Generally the policy stance is that the fault lies with the young woman, who is excluded from school. In some of the harshest approaches she is refused re-admission to any school. In others she may be allowed re-admission after a stipulated period, but not to her former school. This situation 
raises in very stark form a key issue Diana Leonard's scholarship revealed. Her concern with the reproduction of women's subordination through the ways the gender politics associated with families and sexuality interacts with schooling is graphically illustrated here. However, much of the policy literature on pregnancy and exclusion evades an examination of these connected gender dynamics, particularly how and why they interact. In this article I firstly consider the scholarly and policy discussion on schoolgirl pregnancy in Africa as an interlocution with Diana Leonard's work on the family, gender and schooling. I then draw on data collected for three research projects in five African countries involving discussions with education officials, teachers and School Management Committee members. In a wide range of settings harsh portrayals of pregnant schoolgirls and silences or evasion with regard to exclusion are evident. These data emphasise the significance of the insights developed by Leonard regarding the importance of understanding how women's lives are constructed, how they are so often silenced and neglected in policy talk and the significance of examining the connections between the gendered politics of households and schooling. In the Conclusion I discuss some of the policy implications of this perception in the light of emerging debates on expansion of education provision in Africa.

\section{Documenting pregnancy and school exclusion}

In 1997, as a new education system was being developed for a post-apartheid South Africa, Diana Leonard was commissioned by the Gender Education Task Team to write a paper on gender and youth. In this (Leonard, 1997) she synthesised some of her thinking from work in the UK and put down some provocative questions. Her framing of the issues is as pertinent now, fifteen years after it was written as it was then, and it talks very convincingly to work on schools, youth and pregnancy. In writing about education policy she observed the need for

\footnotetext{
...a holistic approach; to see the positioning of each sector of society, each social group, always in relation to the others. So young women must not be ignored (explicitly or implicitly) in studies of events where they were involved...and if and when they are specified, excluded or marginalised...this needs to be noted. Nor must girls and women only be mentioned at the end, as Others, not quite like real youth, as beings who have (added) problems due to (their biology) pregnancy or as special sorts of victims of violence (Leonard, 1997, 2)
}

These remarks, with their stress on relationality and consideration both of how girls are or are not portrayed and what their actual experience is, remains enormously helpful in reviewing the discussion of young women, pregnancy and school exclusion in Africa.

Much of the policy literature on girls' dropout from school in Africa does not mention pregnancy and exclusion. This may possibly be because the numbers of dropouts associated with pregnancy are low in some countries, but, as the debate about the extent of the problem indicates, there is actually relatively limited knowledge about what may be an 
important cause of dropout or push-out. As Leonard remarks, in much of the discussion of this young women and their concerns about exclusion and pregnancy, appear to have been ignored. The annual UNESCO EFA (Education for All) Global Monitoring Report maps trends on school enrolment, progression, retention and financing. The 2011 report notes that large numbers of girls drop out of secondary school. Amongst the reasons presented are the higher costs of secondary schools, which may mean parents privilege sons' schooling over daughters', transport costs, and concern with early marriage (UNESCO, 2011, 76). There is no mention of pregnancy. The remedies proposed are better retention policies for girls in primary school, stipends to support girls at school, and increased labour market opportunities for women to assure parents of a good return on an investment in a girl's schooling (UNESCO, 2011, 77). Neither explicitly nor implicitly does this report raise the question of social mores and views about teenage pregnancies.

This report is not alone in not considering responses to pregnancy as a policy issue. The World Bank Education strategy, published in 2011, noted that a major problem of education provision had been the establishment of more schools and less learning. (World Bank, 2011) The document's stress is on aligning education systems and institutions. It is this, it is claimed, which will deliver results - understood as learning outcomes. Ten actions are singled out as enhancing schooling for girls ${ }^{1}$ (World Bank, 2011, 43). Not one of these addresses the problems of exclusion associated with pregnancy or gendered norms outside school. The ten actions are seen to confirm the view that the levers for change are associated with building an efficient education system, to benefit girls as well as boys. (Ibid).

This focus on learning and the institutions to support it is has become a policy commonplace. In June 2011 the Brookings Institute launched its Global Compact on Learning attracting support from some of the largest charitable foundations, and engaging with all the large bilateral and multilateral organisations in the field of education and international development (Perlman Robinson, 2011). The report highlighted the importance of focusing on equity, and stressed gender and attending to armed conflict would be major areas of concern (Perlman Robinson, 2011, 6). But the aspects of gender inequality commented on were poor girls' low attainment at school, and none of the actions recommended addressed challenging the gender norms inside and outside school that might be responsible for this. In the detailed discussion of reasons for girls' dropout and lack of interest in schooling, poor quality, indirect costs, lack of transportation, and perceptions of low return are cited (Perlman Robinson, 2011, 10). There is a silence about pregnancy and expulsion. While the report does note sexual harassment as a reason girls may not have a safe environment in which to study (Perlman Robinson, 2011, 15) it does not comment on taken for-granted attitudes associated with excluding young mothers, nor consider that this may partly account for drop out and difficulties with attainment. It can be seen that in the

${ }^{1}$ The ten actions are scholarships for girls, recruitment and training of female teachers, girl-friendly curricula and pedagogical approaches that enhance learning and employment, after-school tutoring, and greater support for the non-formal education sector 
policy swing towards focusing on learning the connection between household and school as gendered sites is not being emphasised and support for young mothers' education is not being given detailed attention.

Similarly, in a number of academic discussions on drop out, political observations regarding the links between the gender dynamics of households, school and societies are blurred. For example, Hunt (2008) in an extensive review of a range of reasons for drop out from school in low and middle income countries, places drop out associated with pregnancy in the section on health, not in those dealing with households, social, political or schooling processes. She considers unproblematic research findings that report it is girls with poor school performance, histories of interrupted schooling or low income who tend to become pregnant and withdraw (Hunt, 2008, 26). While she also notes research on institutions requiring girls to leave school when their pregnancy is evident and intimidation when they return (Hunt, 2008, 27), she makes no comment on the gender dynamics of exclusion or the link between private and public sites of discrimination. In her overall comment on a range of different forms of dropout she considers dropout is exacerbated by poverty and needs to be seen as a process, rather than an event. (Hunt, 2008, 52-53) But in this summary and conclusion there is no mention of pregnancy or comment on pervasive gender inequalities. Hunt, like the mainstream policy writers (UNESCO, 2011; World Bank, 2011; Brookings, 2011), implies that pregnancy and exclusion are a series of unfortunate developments in which young women became 'unlucky', rather than a nexus of interconnected gendered exclusions. In this there is a resonance with some of the sex education literature (Adaji et al, 2010; Hindin, 2009) where schools are presented as free-floating sites of instruction implying that knowledge on its own confers protection. Thus the policy literature and some of the academic literature sees drop out, unlike enrolment, as more a problem of schools failing as learning institutions, and less an outcome of the ways in which gendered households, families and schools connect. Leonard's stress on the importance of examining relational dynamics is thus not given appropriate attention.

In challenging the way that young women's multi-faceted relations were often ignored in her 1997 paper Leonard was drawing on many decades of work on gender, the family and the depiction of women as 'dependent, passive, reproduction-driven, non persons' (Leonard and Allen, 1991, x) . Her work took as a starting point the family, which she portrayed as simultaneously a site of gendered reproductive roles, emotional engagement and regulation (Barker, 1976; Delphy and Leonard, 1997). In 1990 she critiqued a turn in the sociology of the family, which meant it was largely women's reproductive work which was analysed, failing to consider the relational dynamic of lives with children, the divisions of class, systemic gender inequalities, and synchronic and diachronic trends over generations (Leonard, 1990). In 2006, reviewing the history of women's education in high income countries, she remarked on the particular policy turn towards gender neutrality that underplayed the importance of complex social relationships (Leonard, 2006). In 1997, she had advised GETT in South Africa to take account of the way that girls may be differently 
located, compared to boys in relation to learning, the family and community duties, and that their responses to this needed to be discussed with them, not in ways that problematised particular kinds of experiences, but appropriately framed through the curriculum (Leonard, 1997, 4). She pointed out that young women may have many different perspectives on pregnancy, not always negative, but that much of the discussion of sex and sexuality drew on heterosexual imperatives, and that there had been inadequate attention given to some of the emerging evidence of coercion associated with some teenage sexuality. She thus called for sex education to focus not only contraception but also on work with boys and men to problematise norms around control and violence, and with girls and women to look at negotiation and desire (Leonard, 1997, 17).

Ideas Leonard formulated had considerable resonance in the work of a number of African scholars, although her particular contribution to the analysis they develop is not cited. In 2002 Bagele Chilisa (2002) reviewed pregnancy and schooling policies in 20 Sub-Saharan African countries. She distinguished between expulsion, continuation and re-entry. Expulsion was practised in 8 countries for which she had data. This entailed young women being forbidden to return to school. Continuation was practised in 4 countries she surveyed. Here young women, who gave birth, could negotiate with their schools the period of maternity leave they would take. Re-entry policies were in place in 8 countries for which she had data. These meant young women were compelled to take a stipulated time away from their studies, but were allowed to return, generally after 12 months, but often not to their original school.

Chilisa linked the difference in policies partly to levels of primary and secondary school provision within the countries she reviewed, and partly to engagements with international conventions, such as CEDAW and CRC, although this was not fully explored. Her detailed work centred on an examination of the re-entry policy in Botswana. She showed how, despite a policy text on re-entry, the practice was for young women, who became pregnant, to leave school and not return. Central to this process was the resonance between cultural norms regarding young women's sexuality and school practices. Thus harsh attitudes to unmarried mothers and their children meshed with school rules that stipulated different times required before readmission was granted to girls and boys. The sense of shame young women reported was exacerbated by age restrictions on re-enrolling and the requirement that they could only be re-admitted to a different school to that which they had attended, often some distance from their family. Chilisa's conclusion was that the coexistence of ideologies about pregnancy and rituals associated with childbirth 'disabled' the majority of young mothers, while the policy language 'constructed and perpetuated' differential treatment between girls and boys (Chilisa, 2002, 22). 'Even when a policy allows girls to reenter the school system, administrative bureaucracy and ideologies of exclusion at the level of the school disable girl mothers, thus perpetuating subtle forms of violence against them' (Chilisa, 2002, 23). What Chilisa was trying to sort out in this analysis was the relationship between gender norms in the family, associated with pregnancy and childbirth, and those 
inscribed in the policy resulting in harsher treatment of girls, compared to boys. In this discussion she positions pregnant schoolgirls as disabled, discriminated against and dishonoured. The connections she makes echo Leonard's formulations regarding the ways young women were so often presented as passive or last in line for attention (Leonard, 1997; Leonard \& Allen, 1991)

Writing nearly ten years later Alice Wekesa (2011) turned this picture somewhat on its head, stressing in her research design and analytical frame the importance of paying attention to the varied views of young mothers. Her study, based in Kenya, engaged in discussion with young women, some of whom had returned to school and some of whom had not. She too stressed how gendered households 'interact' with institutions in school and community. Drawing on a range of feminist economic analyses of households she highlighted how they are gendered sites of decision-making and resource allocation framing the actions of young mothers with regard to schooling. Like Chilisa and Wanda (2006) she shows discursive framings of young mothers as 'contaminated' by pregnancy, and regarded as 'underperforming' students. But her study goes further in that she highlights how contestations in the household over the allocation of female labour for chores and childcare, has a direct bearing on whether young women can exercise their rights to return to school (Wekesa, 2011, 40). This powerful finding extends Chilisa's insights, echoing Diana's Leonard's analysis of the very varied ways in which household labour, including work on kinship networks might produce gender and affect girls' schooling (Dephy and Leonard, 1997; Leonard, 1997, 9; Adkins and Leonard, n.d)

Chilisa, Wekesa and a number of others who comment on the gender inequalities associated with pregnancy and sexual harassment (Bhana, Morrell, Schefer \& Ngabaza, 2010; Nkani and Bhana, 2010; Runhare and Vandeyar, 2011; Dunne, 2008) constitute a feminist riposte to the gender neutrality of the policy analysis and the scholarship that supports this. The feminist work, which travels down a pathway of analysis Diana Leonard marked out, questions a number of features of the standard accounts of girls' dropout. Firstly, as they show, it is much more common for young women to be excluded, because their pregnancy cannot be hidden, than young men. Although some young men do drop out of school in adolescence, often partly because of the many more work opportunities available to them, compared to young women (UNESCO, 2011, page), we cannot simply compare one kind of drop-out with another as though all were forms of the same 'process' . The feminist literature makes clear that dropout associated with stigmatised identities associated with pollution, moral turpitude, or lack of academic commitment, are very different to dropout associated with opportunities to earn money and contribute to a family's livelihood.

Secondly, when assessments of 'just deserts' in relation to schoolgirl pregnancy are made by teachers, head teachers or health professionals it is generally young people who are blamed. Inadequate scrutiny is given to whether or not rape or other forms of gender based 
violence took place, how adults develop curricula and teach about gender equality and reproductive rights, and what levels of access to contraception, health advice and support for young mothers are available. In raising these issues the feminist critique moves away from young mothers' 'bad luck' to more structural issues about sexuality, subordination and the connection of different sites of gender inequality. The education systems approach of the World Bank (2011) in trying to link up school, work and efficient administration fails to recognise the significance of persistent gender inequalities. This silence occludes the need to address these.

Thirdly, to the extent that teachers consider parents part of the problem with schoolgirl pregnancies, it tends to be mothers who are singled out for not providing adequate role models, while issues of the gender stereotypes offered to young men, and sometimes endorsed by relationships with fathers, go unexamined. Feminist scholars, in highlighting the construction of gendered identities and discourses associated with the process of drop out, show it is clearly about more than just economic, political or educational relationships. The complex gender dynamics of households, kin networks, community perceptions and the distillation of these into policy need to be critically examined.

The implication of the feminist scholarship in this area is that the question of schoolgirl pregnancy and the form of gender injustices entailed, may be as much extensive as intensive. That is the depth and nature of the problem may not manifest itself as much in immediately evident large numbers, but rather in the form of discrimination and injustice perpetuated and experienced. The policy response thus needs to be particularly alert to the complexity of local settings and the multi-faceted forms of gender inequalities evident in connected public and private sites. In the next section, drawing on data from studies in five countries I try to map some of the responses articulated by teachers, education officials and SMC members. The pattern highlights how there are silences, attribution of blame and difficulties in making connection across public and private sites. Leonard's (1997) injunction to look carefully at relational dynamics, the differences of social division, and the changes over time remains particularly illuminating.

\section{Three research projects on girls' exclusion from school}

The data discussed to illuminate aspects of the inadequate attention to young women's lives and relationships in putting policy into practice comes from three studies of schooling in Sub-Saharan Africa - GEGPRI (Gender, education and global poverty reduction initiatives), TEGINT (Transforming education for girls in Nigeria and Tanzania) and TENI (Tackling education needs inclusively).

Although none of these studies was designed specifically to examine pregnancy and school exclusion, the theme was considered in the research design and the analysis of all three. The GEGPRI project was designed to examine the implementation of policy on gender, 
education and poverty reduction in Kenya, South Africa and selected global organisations. ${ }^{2}$ From 2007-2010 a multi-country research team collected data for eleven case studies in the national Department/Ministry of Education, a provincial department in each country, a school in each country located in a peri-urban area with high levels of poverty, a local NGO working in a rural setting, global NGOs, and a number of multilateral and bilateral organisations which focussed on gender and education issues (Unterhalter, 2012; Unterhalter \& North, 2011; Dieltiens, Unterhalter, Letsasi \& North, 2009, Karlsson, 2010, North, 2010). Methods included interviews, observations, group discussions and document analysis TEGINT is a partnership between Action Aid, Community Action for Popular Participation (CAPP) in Nigeria and Maarifa ni Ufunguo in Tanzania, funded by Comic Relief and the Tubney Charitable Trust. The project began in 2007 and will run to 2012. The overall goal of the project is to achieve a transformation in the education of girls in Tanzania and Nigeria, enabling them to enrol and succeed in school by addressing key challenges and obstacles that hinder their participation in education and increase their vulnerability to HIV/AIDS. A substantial research component has compared baseline and endline survey research; a number of qualitative studies have been completed collecting interview data, observations and focus group discussions (TEGINT, 2011a; TEGINT, 2011b; Unterhalter and Heslop, 2011; Maschernas, 2012) $)^{3}$. TENI is funded by Comic Relief as a partnership between VSO, the Ghana Education Service and a number of NGOs working to implement series of interventions for inclusive education in Northern Ghana where there are high levels of girls' dropout from school. There is a substantial research component associated with the implementation of the project. In this article I draw on data analysed for the baseline study conducted in 2010-2011. (Unterhalter, North and Longlands, 2011) ${ }^{4}$

In each of the three research projects the question of the exclusion of pregnant schoolgirls came up, sometimes in responses to surveys, sometimes in interviews, and sometimes in policy discussion. In looking across the three datasets a number of themes emerge regarding the ways officials, teachers and SMC members talk about the problem of young mothers and school dropout. The difference from the views of young women is striking.

\section{Silence, distance and evasion}

Silence, social distance and evasion of the difficulties young pregnant women encounter abound in the interview transcripts. Leonard's $(1997,2)$ identification of a process where young women may barely be noticed, even in events which concern them, and generally only as Others or in terms of an essentialised biology associated with pregnancy is particularly illuminating.

\footnotetext{
${ }^{2}$ Gender, education and global poverty reduction funded by the UK Economic and Social Research Council (ESRC) Award no. RES 167-25-260. Thanks to colleagues working on that project (Veerle Dieltiens, Jenni Karlsson, Stu Letsatsi, Herbert Makinda, Amy North, Jane Onsongo and Chris Yates) who collected the data and contributed to the project reflections from which this section of the discussion has developed.

${ }^{3}$ Thanks to TEGINT for permission to quote from unpublished data collected for research studies and to colleagues involved with aspects of the research component of the project, particularly Andrew Mamedu, Oliver Kapaya, Ruth, Duncan Kishekya, Jo Heslop and Louise Wetheridge.

${ }^{4}$ Thanks to TENI
} 
In all the 12 interviews conducted for GEGPRI with gender and education policy makers in global organisations, the question of schoolgirl pregnancies and exclusions was only mentioned once. A UN official, recounted how the purpose of her work had been confirmed to her by a girl in Northern Uganda, abducted by the Lords' Resistance Army, who had returned pregnant to her village after a truce. Although the young girl had to look after a small baby and was recovering from a severe trauma, she had completed primary school. In a village meeting organised for the UN official the young woman asked what the organisation could do to help her continue with secondary education. In commenting on the incident the UN official described how she had worked with a local organisation to secure a scholarship for the girl to attend a secondary school some distance away.

So that's one example of what we are able to do, not at national level, not at district capital level, but going right down to the community level (ntervead of UNGEI Secretariat, Kenya, 27 June 2008,)

She made no mention of what policy or practice changes or discussions might have been required to think about the girl's relationship with her child or the gender dynamics in a family and community trying to work through the grief and suffering associated with sexual violence and abduction and how this might connect with the gender relations at school. The stress in this interview, like virtually all the others with policy makers at the global level, was on securing access and progression in schooling. Thus the multi-dimensionality of relationships is overlooked, while the girl is singled out for comment because of her pregnancy and the fact that she is a victim of violence. Any other kind of gender relationship is not remarked.

A similar distance from the intensity and complexity of the question of schoolgirls who become pregnant was evident in the interviews conducted for the GEGPRI project in the Ministry of Education in Kenya. Participants in a focus group discussion on this theme stressed they were satisfied with the official position which provided for readmission of schoolgirls who had become pregnant after a year, but not to the same school:

Our education system allows for re-admission [of girls who become pregnant] and therefore the Ministry of Education has put up a circular spelling out re-admission policy. Readmission should be ... to another school, not the same school ....When the girl goes back to the same school with the friends and the same teachers she will not be bold enough, confident enough. When she goes to another school things will be normal (Ministry Official during Focus Group Discussion, National Ministry of Education, Kenya: 13 August 2008)

While there was concern, but little detailed commentary on levels of schoolgirl pregnancy, it was felt the official position was adequate because it would ensure international targets were met:
Commented [p1]: 12 separate interviews in 10 different global institutions

Commented [p2]: Found in Q:IFPS \EFPS|CeCeps Work\BFAG Gender Education and Global Povertyldata Cleaned datalglobal transcripts\international institution 08
Commented [p3]: Found in Q:IFPS\EFPS \CeCeps Work\BFAG Gender Education and Global Povertyldata Cleaned data\Kenya\Kenya National Ministry|K_nat ministry_focus group_130808 
... this issue of pregnancy ... impacts on schooling of the girl child. I wanted to say that pregnancy is not an end to schooling. A second chance is always possible so that the girl child can realise her full potentials. So in trying to bring everybody on board we are definitely geared towards realizing universal education for all by 2015 .

(Ministry official, 13 August 2008)

Officials felt it was important to ensure schools were equipped to provide counselling, but there was little discussion of building school capacity to teach about reproductive rights, child protection or engage in discussion of gender with families or the community. It can be seen that the international policy frame stresses the importance of enrolling girls in school and ensuring progression. Girls may require confidence to do this, but there is little concern with thinking about the gender dynamics of norms, families, or schools.

Silence and social distance from the concerns of schoolgirls was also evident in the TEGINT research. For the TEGINT baseline in 2008, 564 girls in the final year of primary school were surveyed in Tanzania and 605 in Nigeria (Unterhalter \& Heslop, 2011, 45). One of the most commonly cited reasons girls said would prevent them completing their schooling was pregnancy. In both countries a substantial proportion mentioned pregnancy as a major reason that might prevent them reaching their desired level of education ( $54 \%$ mentioned this in Tanzania and 32\% in Nigeria (Unterhalter and Heslop, 2011, 31). However, among village officers, teachers and members of school management committees, pregnancy did not feature in the list of reasons they gave regarding why girls might not attend school or fail to complete to a desired level (Unterhalter \& Heslop, 2011, 40). While they did mention the sexual division of labour at home as a reason girls might have difficulty with learning, they tended not to mention gender dynamics at school connecting with relations at home and were silent on the question of pregnancy.

In the focus groups for the TENI baseline children in the last year of primary school did not mention pregnancy with regard to problems they might encounter in completing school, but some mentioned this in relation to others (Unterhalter, North \& Longlands, 2011, 70) suggesting difficulties in talking about and voicing the issue. For this study an inclusion attitude score was developed to try to assess how different groups - mothers, fathers, schoolgirls, schoolboys, teachers, education officials - thought about including girls and children with disabilities. One of the questions used to compile this score investigated attitudes on the inclusion of pregnant schoolgirls. District Education Officers had rather lower inclusion attitude scores than might be expected, given their level of education and access to information. However it appears that their low scores are partly attributable to their negative views on the re-admission of young mothers. (Unterhalter, Longlands and North, 2011, 33 -Summary report). Here too there is a form of social distance, drawing on administrative requirements.

Commented [p4]: Found in Q:IFPS \EFPS\CeCeps Work\BFAG Gender Education and Global Povertyldata|Cleaned data \Kenya Kenya National Ministry\K_nat ministry_focus group_130808 
This data suggests across three studies that the gender dynamics that link home, community and school in relation to pregnancy are not well known or discussed and the views of girls concerning pregnancy are not given high priority. Some officials remark on pregnancy as a problem for girls, which schools could solve if they paid attention to admission. Girls' own fears about pregnancy do not meet with intense policy concern and the relational dynamic between girls and boys is given little attention. These forms of silence and evasion may be associated with the tropes of shame, Chilisa(2002) and Wekesa (2011) noted, but they also recall Leonard's concern (1997) that young women's experience is often ignored

\section{Shame}

Across all three datasets the discussion of schoolgirl pregnancy is often linked with an imputation that what has happened is shameful. The shame is generally directly attached to the girl who, it is suggested, causes a moral or an educational blight., This extract from the GEGPRI dataset, an interview with a Kenyan provincial official, highlights how teachers associate pregnancy with a girl bringing bad results, that is low grades, to a school .

...once they become pregnant in school even the teachers they [want the girls to] leave it. .They [do not want to] take the girls back to school. What they say - because I go to them and ask them [is] 'Why are other communities accepting this girls to come back to school after giving birth? What is the problem with you? ' [ lask] 'why don't you accept the girl?' They say they are going to lower the mean grade (-Kenya Provincial-District official, 25 November 2008)

Teachers stress young mothers' own sense of shame, absolving the school or the adults involved with them:

the problem was that when the girls realise that they are pregnant they disappear from school for ever. The policy [on re-admission] is difficult to implement because they fear that the rest of the pupils will laugh at them (Female teacher during focus group discussion with teachers, Kenya, date unknown)

What is emphasised is that this is a problem for the girl or young woman, not for those with a duty to teach her and support her education. The shame the girls is seen to bring amplifies the social distance teachers feel from poor children and their families, which we have documented elsewhere drawing on the GEGPRI data (Unterhalter, Yates, Makinda and North, 2012). In the extract below the link between blame and shame are evident. The deputy head at the Kenyan school blamed mothers for girls with small children failing to return to school:

There are girls who have been affected like those who dropped out of school because of pregnancy, those who did not come to school because they were told by their mothers to take care of the young baby and some are sold off because parents died
Commented [p5]: Found in Q:IFPS\EFPS\CeCeps Work\BFAG Gender Education and Global PovertyldatalCleaned data|Kenya \Kenya Province and district $\backslash$ K_district_official 08_25112008 
and their step mothers mistreat them. Some run away from home (Deputy Head teacher, Kenya, date unknown)

It can be seen that the Deputy Head, feeling she has to answer for girls failing to attend school, answers with a list of people who are to blame. In her view, it is they, not the school system, who are at fault. The list of those who carry shame is headed by girls who become pregnant. This is followed by mothers who require childcare from their daughters or step mothers who require wages earned by younger girls. The problems she sketches can all be laid at the door of women. It is they who must carry the shame of non-delivery of a school's good track record on enrolment.

This concern to shame girls and their mothers was not articulated everywhere. For example, one national education official in South Africa set out very clearly her understanding of the complex inter-relations:

If you [talk] with girls... they are absolutely traumatized - about their exposure to pregnancy, they are traumatized by harassment from teachers, they are traumatized by levels of sexual violence, they are traumatized by poverty I suppose, the effects of poverty. I presume boys are quite traumatized too, but I don't think we know to what extent. (South Africa National official 13,20 October 2008)

She was concerned with the need to understand more and to draw out the complexity of gender and generational dynamics

[We are looking into research on] why girls fall pregnant - the esteem issues attached to that and also the trend of older men getting into relationships with younger women, which I think is a big issue that affects schools. Many girls that do fall pregnant go back to school quite quickly afterwards ... Families - because of cultural reasons, whatever - it is just acceptable for parents of those kids to take care of their grandchildren. A lot of what's happening is that mothers are taking care of babies and girls are going back to school or studying and boys are allowed to take very little responsibility for parenting - or boys or the older men, whoever the fathers are. We don't really know the extent to which fathers are older men. I suspect that the levels are extremely high. I don't know what the percentage is but we are trying to find out. (South Africa National official 13,20 October 2008)

But this perspective was not shared by all national officials in South Africa. For some pregnancy was the result of youthful experimentation and a response to boredom. Amongst these there was little sympathy with making space for young mothers at school:

Learners are falling pregnant - there's an attitude that needs to change. Little girls say they are bored and therefore hang out with boys. We need to change attitudes - need to find something else to do other than sex when you are bored (Gender Equity Unit National official 27,26 November 2008)
Commented [p7]: Found in Q.JFPSIEFPSICeCeps WorkIBFAG Gender Education and Global Poverty/data|Cleaned data\Kenya \Kenya Schools $\backslash$ K_school_deputy head teacher

Commented [p8]: Found in Q:IFPS \EFPS\CeCeps Work\BFAG Gender Education and Global Povertyldata Cleaned data\S.A\Ministry \DoE\SA_Nat official_13_20102008

Commented [p9]: Found in Q:|FPS|EFPS|CeCeps Work\BFAG Gender Education and Global Poverty/datalCleaned data|S.A\Ministry\DoE\SA_Nat official_13_20102008

Commented [p10]: Found in Q:|FPS\EFPS|CeCeps Work\BFAG Gender Education and Global PovertyldatalCleaned data|S.A|Ministry|Gender Equity Unit\SA_Nat Official_27_GEU_261108 
We do not need mothers in schools. Even in higher institutions we do not need mothers. There are a lot of reasons why girls fall pregnant during school years. We, in the department, cannot ignore the problem. We have to make some interventions. (Gender Equity Unit, National official 24, 25 July 2008)

These more critical attitudes were often voiced by participants in the South African school case study, where the principal, teachers and members of the school management committee expressed ideas about shame, blame and desert that echoed those voiced in Kenya:

In 2007 two learners (from grades 6 and 7) fell pregnant. This was the first time ever that this happened for this school. The parent reported it to the school. The girls merely 'disappeared' and then at the start of 2008 transfer letters were requested. This was lucky since the school management was afraid that the parents might insist on the school taking the child back [as is the provincial policy]. But the parent reported that the child didn't want to be the laughing stock of the school. (Head teacher interview 1,12 March 2008)

It can be seen that the Head teacher expresses shock at the learners becoming pregnant, and his major response is relief that the school management has been 'lucky' in being able to transfer them. He does not dissent from an assessment that the girls are a 'laughing stock'. One male member of the School Management Committee, also commented on how a pregnant schoolgirl is to be associated with bringing a catalogue of disasters to a school and her parents:

I don't agree that this girl after giving birth need not be admitted to the school. However, while she is still pregnant, I think if she's 6 months or 7 months I think it's a waste of parents' money to send that child to school because she will come back to sit and sleep. She should rather stay at home.... The issue of maternity leave was discussed in parliament and they said 'no' to it. It will not be allowed. The maternity leave is for a working person, not persons studying. So if the person is now pregnant at the school, then at 9 months she will give birth there at the school, and there will be a problem at the school as the teachers can't deliver babies; they are not nurses. And if this baby is mismanaged and dies at birth, who will be blamed? Whose problem is that going to be? (School committee member during focus group discussion, 18 March + 2008)

The kind of shame a pregnant schoolgirls was seen to bring was also expressed in this extract from a focus group discussion in one phase of the TEGINT research in Tanzania:
Commented [p11]: Found in Q:IFPS \EFPS\CeCeps Work\BFAG Gender Education and Global Poverty/data|Cleaned data $S$ S.A\Ministry $\backslash$ Gender Equity Unit \SA_Nat Official_24_GEU_25708

Commented [p12]: Found in Q:|FPS\EFPS\CeCeps Work\BFAG Gender Education and Global Povertyldata Cleaned data|S.Alschools datalSA school_Principal interview 1 1 12032008

Commented [p13]: Found in Q:IFPS\EFPS|CeCeps Work\BFAG Gender Education and Global Povertyldata Cleaned data \S.A|schools data\SA_school_Focus Group_18032008 
A schoolgirl, living with her grandmother got pregnant and her grandmother kicked her away... She returned with a one week old baby. Her grandmother agreed to receive her on condition she sends the baby to the parents of the father. She did it but was kicked away. The village government intervened and commanded the father's parents to take care of them. They took her but mistreated her. She was working too much and sometimes they would frame her for stealing. Finally she left the village and I think she went to Dar es Salaam. The whole community abandoned her (Head teacher, Tanzania

It can be seen that the family and community response is one coloured by the notion that the girl has brought shame. The head teacher does not agree with this view, but has not felt able to intervene. Leonard, in writing the analysis for GETT called for more information on household, kinship and community structures and views on sexuality and how they had changed over time (Leonard, 1997, 22). The data reveal that there are indeed many hostile attitudes, but we do not know what shapes them, who expresses them and whether they might change.

\section{Joining up what?}

The third area the data from the three studies highlight is how ill equipped schools, families and education officials are to appreciate the range of issues the exclusion of pregnant schoolgirls raises. The issue of pregnancy connects many different sites of policy and practice, that usually work in separate fields. As discussed above, Hunt's (2008) review of the academic literature saw pregnancy as a health issue. Some national government officials and teachers see it as a problem undermining school attendance or status. District officials and head teachers are concerned to observe regulations. Many school management committee members and village officers do not mention it as a problem. Girls and their families have to confront ideas of shame and exclusion as well as material difficulties, sometimes associated with a girl going to school some distance away or arranging childcare. Leonard, in making recommendations to GETT on youth, pregnancy and gender highlighted the need for the education department to work with the departments of health, Justice, and for curricula to be developed to look not just at the biology but at human relationships. She called for the involvement of sports clubs and the media (Leonard, 1997, 17-18). However multi-dimensional social development is particularly difficult because of the way education systems work in most countries in Africa. Despite the huge investment in attempts to build these in the face of the AIDS epidemic, the success of multi-sectoral initiatives was very uneven (Boler and Archer, 2008; Clarke, 2008; Wood \& Goba, 2011). These difficulties were expressed very clearly by a South African provincial official, interviewed for the GEGPRI research, determined to try to work across sectors on questions of gender;:

We are still compartmentalised. Whatever one does, it's me, it's me and my education. You
Commented [p14]: This piece of data couldn't be located in any of the TEGINT transcripts but was located in the Final Report on the Qualitative Baseline Survey of the Transformative Girls Education Project

Can be found in Q:IFPS \EFPS\CeCeps Work\Action Aid projects \TEGINT\BaselinelQualitative component of baseline \Tanzania qualitative study $\backslash$ Qualitative Baseline 2nd Draft 27Nov2009AFL.doc 
know, in my small corner. ... it's the HIV component in their small corner. And when you try to say 'what are you doing, HIV?' then they think 'you're taking my job'. So when you work together and you move as a block, I think we can achieve. ... At X district - I discovered 72 learners are pregnant and the school is just a few blocks from the district office ...I [would like] bring everyone, Arts and Culture, officials, and then we sit down and we say 'okay, what do we do? Okay, the sports people are here, okay, let's play more sports with these kids and use sports to teach them about sex and sexuality'. You understand? Then the culture person comes up with a programme. But we'd all be working to minimising the level of pregnancy. (District official 1, 16 February 2009)

Here is a vision of a multi-sectoral view about development, made difficult to realise in nonideal conditions, but not so difficult that clear leadership might not accomplish this. She echoes the points Leonard made, and is trying to put some of her aspiration into practice.

\section{Conclusion}

This preliminary review of secondary literature and data from three projects in Africa indicates that we know very little about young women's views on pregnancy, school exclusion, the relationships that support continuing education and those that make it difficult. While some teachers or education officials interviewed for the studies acknowledge the importance of more research on teenage pregnancy and the need for more opportunities to work across departments, a more prevalent view concerns attributing shame to schoolgirls, and silence or evasion on the complexity of the questions teenage pregnancy raises. Gendered dynamics around the portrayal of girls is a key feature of this.

Education policy, currently being formulated in many countries in Africa, is turning to focus on the expansion of secondary schooling. This will make issues of adolescence, sexuality and the treatment of young mothers particularly pertinent (Lloyd, 2011; Plan, 2012). In a very welcome development in Tanzania in 2012 the Cabinet confirmed that young mothers could be re-admitted to school. But,this was enormously contentious. The discussion in this article highlights how popularising the Tanzanian policy and effectively expanding secondary school provision in Africa will require intensive work with teachers, education officials, school committees, girls and young women, boys and young men and the families, household and communities. Leonard's insight is hugely illuminating for this undertaking. She reminds us of the need to see family and schooling not as separate private and public spheres, but as connected sites marked by gender and inter-connected social divisions. She alerts us to the many formations of kin and household groups and the multi-dimensionality of the relational dynamics entailed in the ways they work to produce gender changing over time. She insists we listen to differently placed girls, and do not construct them as problems, but think with them about education. She enjoins us to do policy holistically. It is a clear and compelling message 


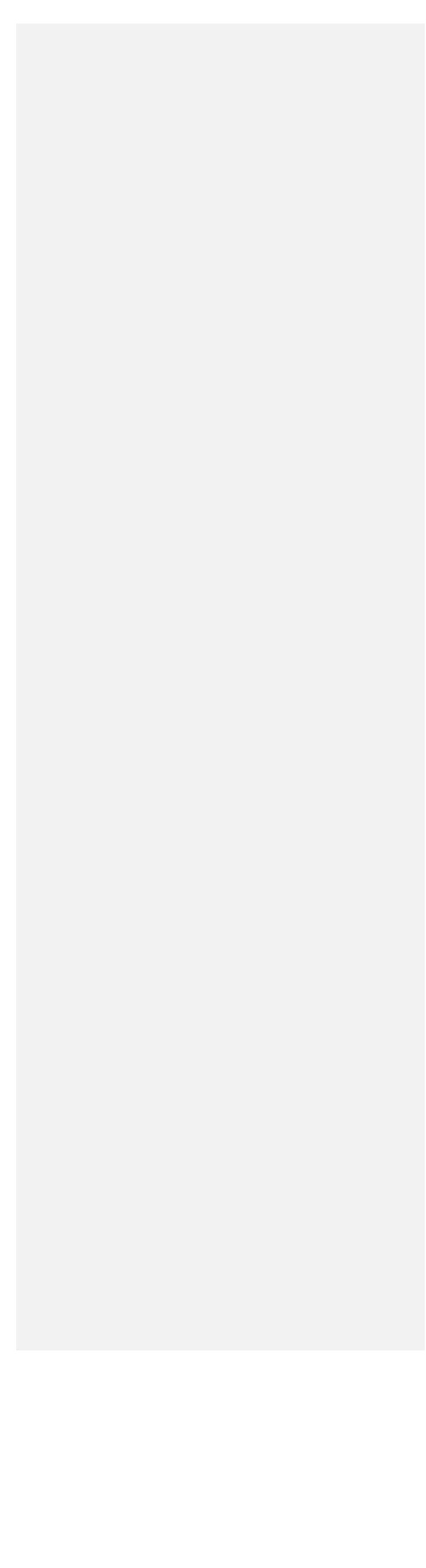




\section{References}

Adaji, S.E. Warenius,L.U., A.A. Ong'any, EA Faxelid e, 2010, 'The attitudes of Kenyan In-School adolescents toward sexual autonomy' African Journal of Reproductive Health ; 14[1]:33-41)

Adkins, L. And Leonard, D., n.d. (c. 2005) 'Young people, kin work and the ggendered constitution of ethnicity'. Unpublished conference paper. Institute of Education, London

Barker, D. L (1976) Dependence and exploitation in work and marriage London: Longman

Bhana, D. Morrell, R. Schefer \& Ngabaza, 2010, 'South African teachers responses to teenage pregnancy and teenage mothers in school' Culture, Health \& Sexuality: An International Journal for Research, Intervention and Care, 12, 8, 871-883

Boler, T. And Archer, D., 2008, The politics of prevention London: Pluto Press

Chilisa, B., (2002),' National policies on pregnancy in education systems in sub-Saharan Africa: the case of Botswana' Gender and Education 14 (1) 21-35.

Clarke, D. 2008, "The road less travelled: gender-based interventions in the education sector response to HIV" in Aikman, S., Unterhalter, E., \& Boler, T. (Eds.) Gender Equality, HIV, and AIDS: A Challenge for the Education Sector. Oxford: Oxfam

Delphy, C.and Leonard, D., 1997, Familiar exploitation. A new analysis of marriage in contemporary western societies Cambridge: Polity

Dieltiens, V, Unterhalter, E, , Letsatsi, S, North, A., 2009 'Gender blind, gender-lite : a critique of gender equity approaches in the South African Department of Education, Perspectives in Education, 27, 4, 365-374.

Dunne, M., 2007, ,'Gender, sexuality and schooling: everyday life in junior secondary schools in Botswana and Ghana', International Journal of Educational Development. 27 (5), 499-511

Eloundou-Enyegue, P.M. (2004) 'Pregnancy-related Dropouts and Gender Inequalityin Education: A Lifetable Approach and Application to Cameroon', Demography 41(3): 509528.

Hindin, M. And Adesegun O 2009' Adolescent Sexual and Reproductive Health in Developing Countries: An Overview of Trends and Interventions International Perspectives on Sexual and Reproductive Health Vol. 35, No. 2 , pp. 58-62

Hunt, F., 2008, Dropping out from school: a cross-country review of literature . CREATE Research Monograph, 16, CREATE Consortium, University of Sussex

Karlsson, J. (2010) Gender mainstreaming in a South African provincial education department: A transformative shift or technical fix for oppressive gender relations? Compare 40(4) 
Leonard, D., 1990, 'Persons in their own right: Children and sociology in the UK' in Chisholm, L. , Buchner, P., Kruger, H.and Brown, P. Eds. Childhood, youth and social change. A comparative perspective Basingstoke: Falmer, 40-48

Leonard, D and Allen,S. Eds. 1991, Sexual divisions revisited Basingstoke: Macmillan Leonard, D., 1997, Gender, youth and education in South Africa. Paper prepared for the Gender, education Task team (GETT), Pretoria: Department of Education

Leonard, D., 2006, 'Gender, change and education' in Davis, K., Evans, M. And Lorber, J. Eds. Handbook of gender and women's studies London: Sage.

Lloyd, C. And Mensch, B.S., 2008, 'marriage and child birth as factors indropping out of school: An analysis of DHS data from Sub-Saharan Africa' Population Studies 62, 1, 1-13.

Lloyd, C., 2011, Evidence paper for DFID Girls' education Challenge Fund Consultancy Report prepared for Department for International Development, London

Mascherenas, O., 2012 forthcoming The role of School Management Committees in promoting girls' schooling Dar es Salaam: ActionAid

Nkani, F.N. and Bhana, D., 2010, 'No to bulging stomachs> Male prinicipals talk about teenage pregnancy at schools in Inanda, Durban' Agenda, Vol. 24, 83,

North,A., 2010, 'MDG3 and the negotiation of gender in international education organisations' Compare 40, 4, 425-440.

Perlman Robinson, J. (2011), A global compact on learning.taking action on education in developing countries Washington: Brooking Centre for Universal Education

Runhare,T. And Vandeyar, 2011, ' Loss of learning space within a legally inclusive education system' Gender \& Behaviour; Volume 9 Number 2, 1-25.

TEGINT, 2011a forthcoming, Analysis of baseline data from schools in which the TEGINT project is working in TANZANIA Dar es Salaam: ActionAid Tanzania

TEGINT, 2011b forthcoming, Analysis of baseline data from schools in which the TEGINT project is working in Nigeria Abuja: ActionAid Nigeria

UNESCO, 2011, EFA Global Monitoring Report. The hidden crisis: Armed conflict and education Paris: UNESCO/Oxford University Press

Unterhalter,E., 2012, Forthcoming 'Silences, stereotypes and local selection: Negotiating policy and practice to implement the MDGs and EFA'In Antoni Verger, Hulya Kosar Altinyelken and Mario Novelli eds. Global Education Policy and International Development: New Agendas, Issues and Policies London: Continuum 
E. Unterhalter \& J. Heslop, 2011, Transforming education for girls in Nigeria and Tanzania. A cross-country analysis of baseline research Johannesburg: ActionAid

Unterhalter, E. And North, A., 2011, ' Responding to the gender and education Millennium Development Goals in South Africa and Kenya: reflections on education rights, gender equality, capabilities and global justice' Compare 41, 4, 495-512

Unterhalter,E., North, A., \& Longlands,H., 2011, Tackling Education Needs Inclusively. Baseline Research Study. Full report prepared for the TENI project London: CECEPS, Institute of Education

Unterhalter, E., Yates, C., Makinda, H. And North, A, 2012 'Blaming the poor: Constructions of marginality and poverty in the Kenyan education sector' Compare 1-21

Wanda, P. (2006), Teen Pregnancy and Education, Politics of Knowledge, Research,

and Practice,' Educational Policy 20 (1) : 59-84.

Wekesa, A., 2011, bending the public-private gender norms: negotiating schooling for young mothers from low income households in Kenya. Working Paper 515, Institute of Social Studies, The Hague.

Wood, L. and Goba, L. 2011, 'Care and support of orphaned and vulnerable children at school: helping teachers to respond' South African Journal of Education 31, 275-290.

World Bank, 2011, Education Strategy Washington: World Bank 